\title{
Effects of Industrial Activities on the Structure and Floristic Pattern of Vegetation within the Calabar Port Authority, South-Southern Nigeria
}

\author{
R. A. Offiong \\ Dept. of Geog. \& Reg. Planning, University of Calabar, Calabar, Nigeria
}

A. I. Iwara

Dept. of Geography, University of Ibadan, Ibadan, Nigeria

Tel: 234-803-945-1970Ｅ-mail: iwaradream2008@yahoo.com

G. N. Njar

Dept. of Geog. \& Reg. Planning, University of Calabar, Calabar, Nigeria

J. E. Atu

Dept. of Geog. \& Reg. Planning, University of Calabar, Calabar, Nigeria

\author{
Received: September 5, $2011 \quad$ Accepted: September 19, $2011 \quad$ Published: March 1, 2012 \\ doi:10.5539/jgg.v4n1p203 URL: http://dx.doi.org/10.5539/jgg.v4n1p203
}

\begin{abstract}
The paper evaluated the effects of industrial activities on the structure and floristic pattern of woody tree/shrub species in the Calabar Port Authority. Three plots of 0.16 ha were employed to collect vegetation parameters (structure and floristic) from vegetation adjoining highly impacted site (HIS) and of less impacted site (LIS). Shannon-Wiener's index showed that vegetation in the LIS was more diverse and heterogeneous than vegetation in the HIS with species diversity index of 2.29 and 2.26 respectively; whereas, the index of evenness revealed what tree/shrub species encountered at the HIS (0.53) were fairly equally abundant compared to tree/shrub species in the LIS (0.44). Vegetation in the LIS was richer at both spatial scale and taxonomic level than vegetation in the HIS, as a result of the favourable edaphic conditions and absence of toxic substances that facilitated vegetation growth. Therefore, to preserve the threatened diversity of available tree/shrub species in the area, government was encouraged to enact laws to stop the destruction and transformation of remaining hectare of vegetation into industrial and residential estates.
\end{abstract}

Keywords: Industrial activities, Calabar Port authority, Floristic composition, Structural composition, Adaptive capacity

\section{Introduction}

Forest vegetation represents an important renewable natural resource with scientific, agricultural, medicinal, pharmaceutical, educational, cultural and ecological values. However, irrespective of these immense ecological values of this species to biotic organisms especially man, anthropogenic activities such as deforestation, pollution, industrialization, habitat destruction and degradation by physical and chemical means are causing significant and irreversible loss to this unique resource (El-Khouly, 2004). The landscape and vegetation of the Calabar Port environment have in the past three decades been subjected to irreversible environmental change, as a result urban and industrial development, agriculture, tourism, and population growth. The Calabar Port ecosystem contributes immensely to the economic development and environmental security of the state and country as a whole. It is noted to contain some virgin forest in the country with abundant resources (Lameed and Ayodele, 2008). The presence of industries and increasing urbanization in the area are immensely affecting the forest resources available. Indeed, the developmental efforts of the government and entrepreneurs in opening up 
areas for access to and fro the area have resulted in the removal of vegetation and subsequent degradation of the environment.

The operations and effluent management of industries in the Calabar Port Authority in relation to other municipal wastes negatively impact on the wetlands, coastal and terrestrial ecosystem of the port environment. The industrial activity in the area includes food processing, fuel bunkering, tanneries, corrugated iron sheets, logging, shipping as well as municipal waste disposal. These activities result in soil pollution through the continuous discharge of untreated effluents, thereby increasing the levels of heavy metals in the soil. The concentration of heavy metals such as lead, oil and grease, copper, bromide, mercury, aluminum, zinc among others in large quantities induces many biochemical and structural changes in the biological systems of the plants (Kabir et al., 2008), which inhibit plant growth. There is however urgent need to address the depletion of the area's rich biodiversity to avoid inherent impacts (such as alteration in temperature, flood, accelerated soil erosion, soil loss etc) on the survival of man especially, the generations to come. Perhaps, the most serious risks of industrial production activities in the area include air and water pollution from the discharge of effluents (in both gaseous, solid and liquid forms) without prior treatment into rivers, estuaries, lagoons, soil, vegetated areas and into the atmosphere. This of course is of great concern to the terrestrial and aquatic environment. The danger associated with these heavy metals on the environments stems from the fact that, they are not only toxic, but have cumulative or synergistic effects on terrestrial and aquatic resources when combined (Lameed and Ayodele, 2008; Muwanga and Barifaijo, 2006).

Indeed, the continuous growth and expansion of industries in the Calabar Port environment is causing massive environmental pollution with inherent impacts on plants growth. Vegetation in the port authority differs one from location to the other depending on the extent of pollution. Polluted soil is noted (Kabir et al., 2010) to alter plant growth and quality, and the effects are often destructive. However, with the daily industrial activities and expansion of the work environments like the tank farm that is ongoing, the natural forest vegetation of the Calabar Port environment is drastically modified and altered resulting in structural and floristic changes, loss of habitat, and pollution of streams and disappearance of watersheds among others. Information on flora composition, diversity and biomass is absolutely essential in understanding forest ecosystem dynamics and conservation; as it may be a tool to estimate the level of adaptation to the environment and their ecological significance (Raddy et al., 2008). However, for sustainable development, management and conservation of the remaining vegetation in the area in line with the global call for forest protection as sequester of $\mathrm{CO}_{2}(\mathrm{carbon}$ sink), it becomes imperative to evaluate the impacts industrial activities have on woody tree/shrub species in order to ascertain the ecological status of vegetation in the Calabar Port Authority and to call for its protection. This study is therefore relevant because it would contribute to the existing gap in knowledge; as there are paucity of documented studies that have examined this effect, despite the existence of the Calabar Port Authority for decades as a business hub of Cross River State.

\section{Review of Related Literature}

The quest for man's continued existence on planet earth has led to the modification of vegetation causing tremendous changes to the world ecosystems. Vegetation which helps to regulate the flow of numerous biogeochemical cycles, most critically those of water, carbon, and nitrogen has been destroyed due to man's desire to make living worthwhile (Iwara et al., 2011). The need for the improvement in living standards such as industrial and residential expansion has led to the wanton destruction and pollution of forest vegetation. Pollution effects are indeed many and wide-ranging. There is no doubt that excessive levels of pollution are causing a lot of damage to biotic organisms including tropical rainforest. Several scholars have perhaps raised concern regarding the destruction of forest for various non-agricultural uses. For instance, Baskaran et al., (2009) assert that industrialization is an important tool for development of any nation, but they argue that industrial activity has expanded so much all over the world that today; it has become a matter of major concern in the deterioration of the environment. With the growth of industries (sugar, paper, tannery, textile, sago, dye industries), pollution of natural ecosystem by industrial waste water has increased tremendously. The effluents not only affect plant growth but also deteriorate soil properties, thereby hindering plant's growth. Robin and David (2001) contend that the present levels of anthropogenic activities are rapidly altering natural habitat giving almost no time to local biota to develop adaptations. This results in irreversible variations in existing vegetal cover. They further argue that habitat destruction is the major cause of species extinctions.

Seenivasan et al., (2008) note that industrial growth is causing an enormous environmental pollution. They note that industrial activities result in the pollution of soil; as polluted soil can alter plant growth and quality, and the effects are often destructive. Kabir et al., (2008) with similar view report that lead is a toxic environmental contaminant that induces many biochemical and structural changes in biological systems. McLaughlin et al., 
(1999) posit that heavy metal contamination of soils due to intensive industrial activities and agricultural development usually causes environmental problems. Elevated levels of heavy metals not only decrease soil microbial activity and crop production, but also threaten human health through the food chain. Dave and Krishnayya (2004) assert that species diversity varies greatly through space and time. Disturbance they argue is widely believed to be one of the main factors influencing variation in species diversity. Disturbance is a discrete event that abruptly destroys or displaces individual, by directly or indirectly changing the availability of substrate and /or other resources and creates an opportunity for new individuals to become established. In similar manner, Remegie and Yansheng (2008) submit that human disturbance like selective logging or cultivation seems to have an influence on plant species diversity. They contend that after disturbance, a habitant is more heterogeneous because of small, sunny gaps beside dense forest, different microclimate conditions in a near distance among others. These heterogeneous environments offer diverse possibilities for high amount of different species.

Kitazawa and Ohsawa (2002) believe that various habitats can be regarded as spatially and temporally dynamic patches of vegetation being subjected to diverse human interference. Kitazawa and Ohsawa allege that human activities can decimate or impoverish local and regional biota. Human they maintain have altered ecosystems to varying degrees and the resultant array of natural, semi-natural and human made ecosystems within a landscape can be conceived as constituting both a readily measurable gradient of land use and a more complex gradient of anthropogenic effects. Pitchairamu et al., (2008) in a study carried out to examine the floristic inventory and quantitative vegetation analysis of Tropical Dry Deciduous Forest in Piranmaali Forest, India discovered that tree species richness varies along the disturbance gradient in different stands. They reported that the undisturbed stand showed the highest species richness (11-9); species richness was lowest (5-4) in the disturbed stand, while in the moderately disturbed stand; the diversity was somewhat higher (8-7). They however concluded that tree species varied according to the disturbance gradient in different stands. Pickett and White (1985) assert that disturbance of an ecosystem means any discrete event that disrupts the ecosystem, community or population structure, or the physical environment. Species composition, community dynamic and ecosystem services of forest ecosystems become adversely affected by disturbances of both natural and anthropogenic origin. They classified disturbance into large scale or community wide (landslides, volcanoes, drought, lightening, forest fire and various human activities) and small-scale disturbance such as mortality of few trees. The review of literature apparently reveals that industrial activities characterized by forest destruction and discharge of untreated wastes on the environment exert tremendous effects on the world's ecosystems (terrestrial and aquatic). The indiscriminate discharge of untreated waste in whichever form on land increases the levels of heavy metals in the soil, which in the long-run leads to structural and floristic changes. The composition, diversity and structure of vegetation are important factors for assessing biological diversity of forest ecosystem because they give vital information on plants' adaptation to changes in environmental conditions within or above their level of tolerance.

\section{Materials and Methods}

\subsection{Study Area}

The study area was carried out within the work environment of Calabar Port Authority (NPA). The Calabar Port Authority lies between latitude $0500^{\prime} 40^{\prime \prime} \mathrm{N}$ and longitude 008 19'04'"E (GPS readings). The area has temperature of $27{ }^{\circ} \mathrm{C}$, and rainfall ranges between $2000 \mathrm{~mm}-3000 \mathrm{~mm}$ reaching its peak within the month of July and August; with a relative humidity of about $80 \%$. It has a luxuriant topography which heads seaward; the soils are basically clayed-loamy. It also has luxuriant vegetation dominantly occupied by oil palms, grasses, herbs, Alstonia boonei, Anthocleista vogelii, Terminelia spp, nypa palms and cultivated crops. The area is basically an industrial zone comprising of primary, secondary and tertiary industries. The industries in the area include food processing industries, fuel bunkering activities, tanneries, metal works, building materials and engineering industries, logging activities, shipping services and financial institutions among others. These industries through their numerous production activities have impacted tremendously on the biophysical components of the Calabar Port ecosystem mostly soil and vegetation. The vegetation of the area has been seriously modified due to the continuous expansion of industrial units and the indiscriminate disposal of toxic substances.

\subsection{Vegetation Sampling and Data Collection}

This study assessed the impact of industrial activities on the structure and floristic pattern of woody tree/shrub species within the Calabar Port Authority, by comparing vegetation parameters (structure and floristic) adjoining highly impacted area (Calabar Port Authority) with those of less impacted site (in Odukpani as control). The study sites have similar climate, but have different anthropogenic activities. The highly impacted site (HIS) 
(Calabar Port Authority) is completely an industrial estate with patches of farmlands, as such is mostly polluted by the discharge of untreated industrial effluents, while the less impacted site (LIS) is characterized by fallows as a result of farming activities and sporadic logging as well as fuel wood harvesting activities. The vegetation of both communities is purely fallow with patches of woodland. The heavy metal found in the highly impacted site includes caustic soda, dye, hydrocarbons, lead and fecal coliform.

Two belt transects of $80 \mathrm{~m}$ with interval of $5 \mathrm{~m}$ in-between were laid in the two study sites. In each site, four quadrats measuring $40 \mathrm{x} 40 \mathrm{~m}$ were laid out of which three were randomly selected for estimating vegetation attributes. In all, six quadrats (three in the highly impacted site and three in the less impacted site) were selected and studied. However, in each quadrat, all woody stems $\geq 10$ centimeters $(\mathrm{cm})$ diameter at breast height (DBH $130 \mathrm{~cm}$ from the ground) were counted regardless of trees or shrubs species. Other vegetation components examined in each quadrat were number of tree/shrub species, , tree height, crown and basal cover. Basal cover and crown cover were determined using the line transect method (Jennings et al. 1999; Coulloudon et al.1999); tree diameter was obtained using measurement at breast height of 130cm (Hall and Okali, 1979); tree height was measured using the trigonometry approach (in each quadrat, only tree species with the highest canopy was measured) (Offwell Woodland and Wildlife Trust, 2000).

\subsection{Data Analysis}

The vegetation data were quantitatively analysed for species diversity, relative density, relative frequency, relative dominance, basal area, Importance Value Index (IVI) and species evenness. The Importance Value Index (used to determine dominance of tree/shrub species in the two vegetation communities) for the enumerated tree species was determined as the sum of the relative density, relative frequency and relative dominance. The various vegetation analytical methods employed are shown below:

Basal Area (BA) for each plot was calculated using the formula given by Cintron and Novelii (1984); Adams et al., (2007) as:

$$
\text { Basal Area }(\mathrm{BA})=0.7857 \times \mathrm{X} \mathrm{D}^{2}(\mathrm{~cm})
$$

Where: $\mathrm{D}=$ Diameter at breast height taken at $137 \mathrm{~cm}$

Importance Value Index (IVI) for every species in each plot was calculated using the equation given by Cintron and Novelii (1984) and Adams et al., (2007) as:

$I V I=$ Relative density $\left(R_{d}\right)+$ Relative frequency $\left(R_{f}\right)+$ Relative dominance $\left(R_{D}\right)$

Where:

$$
\begin{gathered}
\mathrm{R}_{\mathrm{d}}=\frac{\text { No. of trees of species } \mathrm{A}}{\text { Total No. of all tree species }} * 100 \\
\mathrm{R}_{\mathrm{f}}=\frac{\text { Frequency of occurrence of species } \mathrm{A}}{\text { Total frequency of all species }} * 100 \\
\mathrm{R}_{\mathrm{D}}=\frac{\text { BA of all trees of species } \mathrm{A}}{\text { Total BA of all species }} * 100
\end{gathered}
$$

Species Diversity Index for the two communities was calculated using Shannon-Wiener's Index given by Price (1997) as:

$$
\begin{gathered}
\mathrm{H}^{1}=\mathrm{S}-\Sigma \mathrm{Pi} \log _{\mathrm{e}} \mathrm{Pi} \\
\mathrm{I}=1
\end{gathered}
$$

Where: $\mathrm{H}^{1}=$ Shannon-Diversity Index; $\mathrm{S}=$ total no. of tree/shrub species in each community; $\mathrm{Pi}=$ the proportion or relative abundance of individual tree/shrub species; $\log _{e}=$ Natural logarithm.

Species Evenness Index for the two communities was calculated using Shannon-Wiener's Index given also by Price (1997) as:

$$
\mathrm{E}=\mathrm{H}^{1} / \log _{\mathrm{e}} \mathrm{S}
$$

Where: $\mathrm{E}=$ Shannon-Wiener's Evenness Index; $\mathrm{H}^{1}=$ Shannon-Diversity Index for each study community; $\mathrm{S}=$ total no. of tree/shrub species in each community and $\log _{e}=$ Natural logarithm. 
Test of significance: Independent T-test statistical technique was used to determine differences in tree growth variables (crown cover, basal cover, and tree size or DBH as well as tree height) between the two vegetation communities. The analysis was done using statistical package for social sciences (SPSS) 17.0 for Windows.

\section{Results and Discussion}

\subsection{Floristic Composition of Woody Tree/Shrub Species}

In the highly impacted site (HIS), 67 woody stems of 11 tree/shrub species belonging to 9 families were encountered, while 191 woody stems of 14 tree/shrub species belonging to 12 families were recorded in the less impacted site (LIS) (Table 1). Mean stem density was 55 trees/shrubs per plot or 0.04 ha for vegetation in the LIS, while that for the HIS was 23 trees/shrubs ha ${ }^{-1}$. The Vegetation in the LIS was more diverse, richer and heterogeneous at both spatial scale and taxonomic levels than vegetation in the HIS. This variation in the composition of woody tree/shrub species was attributed to the industrial activities prominent in vegetation adjoining NPA work environment which probably made it unfavourable for trees/shrubs to adapt to the area. The discharge of toxic substances inhibits the growth of tree/shrub species. Indeed, the retention and presence of toxic pollutants in the area greatly decreased the habitat potential of flora in the region. This result corroborates earlier studies like those of Uzair et al. (2009) Kabir et al. (2010) that the presence of toxic substances in the soil limits flora potential of the area. In the HIS, Apocynaceae, Arecaceae and Fabaceae were the most abundant families with 19, 19 and 9 tree/shrub species respectively; whereas, in the LIS, only Fabaceae was the most abundant family with 26 tree/shrub species. The density of trees in the two vegetation communities differed significantly $\left(\mathrm{t}_{\text {cal }}=11.085, \mathrm{t}_{\text {crit }}=2.776\right)$.

Also, results in table 1 showed that vegetation in the less impacted site was richer, more diverse and heterogeneous than vegetation in the highly impacted site with species diversity indices of 2.29 and 2.26 respectively. In addition, the index of evenness obtained for vegetation in the highly impacted site (0.53) revealed what tree/shrub species encountered along were fairly equally abundant compared to tree/shrub species in the less impacted site (0.44) that showed discernible pattern of dominance in occurrence and distribution by tree/shrub species like Elaeis guineensis, Alstonia boonei, Musanga cecropioides, Anthocleistra vogelii and Terminelia superb. The presumably reason for the moderate species diversity obtained for vegetation in the highly impacted site could be that either that the impact of industrial disturbance was not enough to eradicate all the tree/shrub species from the area or that tree species might have survived the disturbance due to their adaptive capacity (Kuss, 1986; Adnan and Rashid, 2001).

\subsection{Structural Composition of Woody Tree Species}

Information on the structure of vegetation in the study communities is shown in table 1. Total basal area for woody stems with $\geq 10$ centimeters $(\mathrm{cm})$ diameter at breast height measured for vegetation in LIS was $28016.72 \mathrm{~cm}^{2}$ with mean value of $9338.91 \mathrm{~cm}^{2} / \mathrm{ha}$, woody stems in the HIS was $4538.46 \mathrm{~cm}^{2}$ with mean value of $1512.0 \mathrm{~cm}^{2} /$ ha. However, the distribution of tree size across the 0.04 ha plots using DBH interval classes revealed the dominance of big stemmed individuals in the less impacted site (LIS), tree species increased with increasing girth (stem diameter) and girth class of $91-120 \mathrm{~cm}$ recorded the highest number of individuals or stems of 86; while the girth interval classes for vegetation in the highly impacted site (HIS) was dominated by small stemmed individuals with girth class of $31-60 \mathrm{~cm}$ having the highest number of stems (Figure 1). The low tree/shrub growth variables in terms of basal cover, crown cover, tree size (DBH) and tree height in the highly impacted site compared to those in the less impacted site was attributed to the varying site disturbances such as gravel deposition, farming activities and the discharged of toxic substances. These series of disturbances are reported (El-khouly, 2004; Kabir et al., 2010) to have significant effects on the establishment and growth of plants. The high structural distribution of vegetation parameters in the less impacted site was due to the relatively low level of disturbances, as the ecological status of the vegetation was near stable. Another possible reason according to Aweto (2001) is the favourable site condition like the abundance of sapling, facilitating ecological succession. The result of independent samples test showed that basal area and tree size varied significantly between the two vegetation communities $\left(\mathrm{t}_{\text {cal }}=12.00, \mathrm{t}_{\text {crit }}=2.776\right.$ and $\left.\mathrm{t}_{\text {cal }}=14.623, \mathrm{t}_{\text {crit }}=2.776\right)$.

Tree distribution by height indicated that a total of $84.74 \mathrm{~m}$ was measured across the 3 plots in the less impacted site with a mean value of $28.25 \mathrm{~m} /$ ha (Table 1); the tallest tree/shrub species in the LIS were Albizia zygia $(35.12 \mathrm{~m})$, Alstonia boonei $(27.08 \mathrm{~m})$ and Musanga cecropioides $(22.54 \mathrm{~m})$; while in the highly impacted site, a total of $47.46 \mathrm{~m}$ was measured across the 3 plots with a mean value of $15.82 \mathrm{~m} / \mathrm{ha}$. The tallest tree/shrub species were Terminelia superb $(18.96 \mathrm{~m})$, Elaeis guineensis $(15.34 \mathrm{~m})$ and Alstonia boonei $(13.16 \mathrm{~m})$. The height of trees in the two communities differed significantly $\left(\mathrm{t}_{\text {cal }}=3.070, \mathrm{t}_{\text {crit }}=2.776\right)$ with trees in the less impacted site showing better canopy structure. This structural characteristic was attributed to favourable site conditions like 
richness of nutrients, abundance of sapling, and absence of industrial effluents (Reddy et al., 2008; Aweto, 2001). Total basal and crown cover for woody stems with $\geq 10$ centimeters $(\mathrm{cm})$ diameter at breast height measured across vegetation in LIS were $31.1 \%$ and $262.7 \%$ with mean values $10.4 \%$ and $87.6 \%$ respectively, while those in the HIS were $16.9 \%$ and $147.6 \%$ with mean values of $5.6 \%$ and $49.2 \%$ respectively. The reason for this apparent variation $\left(\mathrm{t}_{\mathrm{cal}}=3.342, \mathrm{t}_{\text {crit }}=2.776\right.$ and $\left.\mathrm{t}_{\mathrm{cal}}=7.913, \mathrm{t}_{\text {crit }}=2.776\right)$ was the differences in disturbance gradients.

\subsection{Ecological Dominance of Woody Tree Species}

Dominance which is calculated as the Importance Value Index (IVI) for different tree species varied in relation to individual species' adaptive and tolerant capacity. For this study, the IVI for five tree species with the highest number of stems was estimated (Table 2). The Table showed that in the LIS, Elaeis guineensis was the most ecologically dominant and adaptive tree species with relative density of $22.10 \%$, relative frequency of $21.43 \%$ and relative dominance of $24.79 \%$; it was closely followed by Alstonia boonei with relative density of $29.47 \%$, relative frequency of $21.43 \%$ and relative dominance $15.86 \%$. The third tolerant and adaptive tree species was Musanga cecropioides with relative density of $21.605 \%$, relative frequency of $21.43 \%$, and relative dominance of $22.74 \%$. However, other tree species with wide spatial distribution and speciation were Terminelia superb and Anthocleistra vogelii with IVI of 52.25 and 47.44 respectively. The presence of large of these ecologically dominant and adaptive tree species revealed a high level of floristic overlap in the forest vegetation due to its moderate stable state and favourable edaphic conditions. The dominance of these tree/shrub species in the LIS was attributed to the abundance of propagules or seeds that facilitated ecological succession (Iwara et al., 2011; Aweto, 2001).

Furthermore, table 2 gives information on the dominance of tree/shrub species in the HIS. It thus revealed that Alstonia boonei was the most ecologically dominant and adaptive tree species. It had relative density of $36.67 \%$, relative frequency of $25 \%$ and relative dominance of $22.79 \%$; the second ecologically dominant species in the disturbed zone was Elaeis guineensis with relative density of $20 \%$, relative frequency of $25 \%$ and relative dominance of $31.47 \%$. The third dominant and ecologically adaptive species was Anthocleistra vogelii with relative density of $26.67 \%$, relative frequency of $25 \%$ and relative dominance of $17.45 \%$. The low level of floristic overlap noticed in the HIS was attributed to the various disturbance regimes that characterized the area like site expansion and the discharge of toxic substances that inhibited the establishment and growth of vegetation. These conditions slow down plant growth (Uzair et al., 2009). In addition, Nypa fruiticans dominated the ocean margins and constituted the major riparian tree species in the HIS, while Alstonia Boonei, Elaeis guineensis, Anthocleistra vogelii, Harungana madagascariensis and Pandanus candelabrum dominated the hinterland.

\section{Conclusion and Recommendations}

This study shows that flora and their environment provide a better understanding of the ecological consequences of disturbance, as depicted in the result obtained. The vegetation in the LIS was more diverse and heterogeneous at both spatial scale and taxonomic levels than vegetation in the HIS. The low density and composition of woody tree/shrub species in the HIS is attributed to the indiscriminate discharge of toxic substances which make soil of the area unfavourable for plant growth This is because plants under stressed conditions are most likely to be adversely affected by high concentration of toxic substances. For instance, lead exerts deleterious effects on morphology, growth and photosynthetic processes of plants and causes inhibition of enzyme activities, water imbalance, alterations in membrane permeability and disturbs mineral nutrition. The results obtained for vegetation in the Calabar Port environment (HIS) indicate that industrial activities strongly influence the growth of flora communities; as the population of stress tolerant and resilient tree/shrub species increases, while the population of intolerant and non-resilient species decreases with increasing disturbance frequency and regime. Though, the forest vegetation of the Calabar Port Authority is highly threatened, the diversity of available flora species can be protected to facilitate rapid ecological regeneration and restoration. On this note, government is encouraged to enact laws to stop the destruction and transformation of the remaining hectare of vegetation into industrial estate. If this is urgently implemented, it would not only preserve the rare and endemic flora of the area, but sustain the ecological integrity of ecosystems of the landscape which has high environmental potentials mostly in the era of emerging climate change disasters.

\section{References}

Adam, J. H., Mahmud, A. M. \& Muslim, N. E. (2007). Cluster Analysis on Floristic Composition and Forest Structure of Hilly Lowland Forest in Lok Kawi, Sabah State of Malaysia. International J. of Botany, 3 (4), 351-358. http://dx.doi.org/10.3923/ijb.2007.351.358 
Adnan, M. N. \& Rashid, A. (2001) Effect of Road Construction on Phytogeography of Herbaceous Flora in Areas Adjacent to Balakot - Shogran Road, Mansehra District, N. W. F. P., Pakistan. Online Journal of Biological Sciences, 1(4), 232-234

Aweto, A. O. (2001) Trees in Shifting and Continuous Cultivation Farms in Ibadan Area, Southwestern Nigeria. Landscape and Urban Planning, 53, 163-171. http://dx.doi.org/10.1016/S0169-2046(00)00151-1

Baskaran, L., Sundaramoorthy, P., Chidambaram, A. L. A., et al. (2009) Growth and Physiological Activity of Greengram (Vigna radiata L.) Under Effluent Stress. Botany Research International, 2(2), 107-114.

Cintron, G. \& Novelii, Y. S. (1984). Methods for Studying Mangrove Structure” in S. Snedakar and J.S. Snedakar (eds) The Mangrove Ecosystem Research Methods. UNESCO, United Kingdom, pp 91-114.

Coulloudon, B., Eshelman, K., Gianola, J., et al. (1999). Sampling Vegetation Attributes. Technical Reference 1734-4, U.S. Department of Agriculture, Natural Resource Conservation Service, Grazing Land Technology Institute.

Dave, M. \& Krishnayya, N. S. R. (2004). Habitat Alternation and Floristic Changes in and around Harni Pond Baroda, India. Tropical Ecology, 45(2), 293-302.

El-khouly, A. A. L. (2004). Effect of Human Activities On vegetation Diversity in Siwa Oasis. International .Confernce on Water Resources and Arid Environment.

Hall, J. B. \& Okali, D. U. U. (1979). A Structural and Floristic Analysis of Woody Fallow Vegetation near Ibadan, Nigeria. J. Ecol., 67, 321-346. http://dx.doi.org/10.2307/2259354

Iwara, A. I., Offiong, R. A., Ogundele, F. O. \& Ibor, U. W. (2011). Effect of Land Use Change on the Structure and Floristic Pattern of Vegetation in Ugep, Cross River State, South-Southern Nigeria. Article in Press, Botany, Canada.

Jennings, S. B., Brown, N. D. \& Sheil, D. (1999). Assessing Forest Canopies and Understorey Illumination: Canopy Closure, Canopy Cover and other Measures. Forestry, 72(1), 59-74. http://dx.doi.org/10.1093/forestry/72.1.59

Kabir, M., Iqbal, M. Z., Shafiq, M. et al. (2010). Effects of Lead on Seedling Growth of Thespesia populnea L. Plant Soil Environ., 56(4), 194-199.

Kabir, M., Zafar Iqbal, M., Farooqi, Z. R. et al. (2010). Vegetation Pattern and Soil Characteristics of the Polluted Industrial Area of Karachi. Pak. J. Bot., 42(1), 661-678.

Kitazawa, T. \& Othsawa, M. (2002). Patterns of Species Diversity in Rural Herbaceous Communities Under different Magt Regima. China, Central Japan. Biological Conservation, Vol. 104. http://dx.doi.org/10.1016/S0006-3207(01)00170-7

Kuss, F. R. (1986) A Review of Major Factors Influencing Plant Response to Recreation Impacts. Environ. Manage., 10, 637-650. http://dx.doi.org/10.1007/BF01866768

Lameed, G. A. \& Ayodele, A. E. (2008). Environmental Impacct Assessment of Cement factory production On Biodiversity: A Case Study of UNICEM Calabar, Nigria. World J. of Biological Research, 1(1), 1-10.

McLaughlin, M. J., Parker, D. R. \& Clarke, J. M. (1999). Metals and Micronutrients-Food Safety Issues. Fields Crop Res., 60, 143-163. http://dx.doi.org/10.1016/S0378-4290(98)00137-3

Muwanga, A. \& Barifaijo, E. (2006). Impact of Industrial Activities on Heavy Metal Loading and their Physico-Chemical Effects on Wetlands of Lake Victoria Basin (Uganda). African Journal of Science and Technology (AJST), Science and Engineering Series, 7(1), 51-63.

Offwell Woodland \& Wildlife Trust. (2000). How to Calculate the Height of a Tree. Retrieved from http://www.offwell.free-online.co.uk/wet_wood_survey_2001/height.ht

Pickett, S. T. A \& White, P. S. (1985). The Ecology of Natural Disturbance and Patch Dynamics. Orlando: Academic Press, Florida.

Pitchairamu, C., Muthuchelian, K. \& Siva, N. (2008). Floristic Inventory and Quantitative Vegetation Analysis of Tropical Dry Deciduous Forest in Piranmal, Forest, Eastern Ghats, Tamil Nade, India. Ethnobotanical Leaflets, 12, 204-216.

Price, P. W. (1997). Insect Ecology. Third Edition. New York: John Wiley and Sons Inc. 
Reddy, S., Babar, S., Giriraj, A., et al. (2008). Structure and Floristic Composition of Tree Diversity in Tropical Dry Deciduous Forest of Eastern Ghats, Southern Andhra Pradesh, India. Asian J. of Scientific Research, 1 (1), 57-64. http://dx.doi.org/10.3923/ajsr.2008.57.64

Remegie, N. \& Yansheng, G. (2008). Anthropogenic Impacts on Protected Areas of Burundi: Case Study of Ruvubu National Park. The Journal of American Sciences, 4(2), 26-33.

Robin, L. M \& David, J. C. (2001). The Diversity Disturbance Relationship: Is it Generally Strong and Peaked? Ecology, 82.

Seenivasan S., Manikandan N., Muraleedharan N. N. et al. (2008). Heavy Metal Content of Black Teas from South India. Food Control, 19, 746-749. http://dx.doi.org/10.1016/j.foodcont.2007.07.012

Uzair, M., Ahmed, M. \& Nazim, K. (2009). Effect of Industrial Waste on Seed Bank and Growth of Wild Plant in Dhabeji Area. Pakistan Journal of Botany, 41(4), 1659-1665.

Table 1. Consolidated details of vegetation inventory in the two communities

\begin{tabular}{|l|c|c|}
\hline Description & Less Impacted Site (LIS) & Highly Impacted Site (HIS) \\
\hline No. of tree/shrub species & 14 & 11 \\
\hline No. of families & 12 & 9 \\
\hline Density (no. of stems)* & $191(55 \pm 2.3)$ & $69(23 \pm 1.7)$ \\
\hline Species diversity index & 2.29 & 2.26 \\
\hline Species evenness index & 0.44 & 0.53 \\
\hline Basal area $\left(\mathrm{cm}^{2}\right)$ & $28016.72(9338.91 \pm 627.09)$ & $4538.46(1512 \pm 179.14)$ \\
\hline Height $(\mathrm{m})^{*}$ & $84.74(28.25 \pm 3.68)$ & $47.46(15.82 \pm 1.69)$ \\
\hline Crown cover $(\%)^{*}$ & $262.7(87.6 \pm 3.7)$ & $147.6(49.2 \pm 3.1)$ \\
\hline Basal cover $(\%)^{*}$ & $31.1(10.4 \pm 0.3)$ & $16.9(5.6 \pm 1.4)$ \\
\hline Tree size $(\mathrm{cm})^{*}$ & $326.70(108.9 \pm 3.7)$ & $131.2(43.7 \pm 2.5)$ \\
\hline
\end{tabular}

*Difference between means is significant at $5 \%$ alpha level

Table 2. Ecological dominance of top 5 woody tree /shrub species

\begin{tabular}{|l|l|l|l|l|l|l|l|l|}
\hline LIS Species & Family & $\mathrm{BA}\left(\mathrm{cm}^{2}\right)$ & $\mathrm{R}_{\mathrm{D}} \%$ & $\mathrm{D}$ & $\mathrm{R}_{\mathrm{d}} \%$ & $\mathrm{~F}$ & $\mathrm{R}_{\mathrm{f}} \%$ & $\mathrm{IVI} \%$ \\
\hline Elaeis guineensis & Arecaceae & 7091 & 24.79 & 21 & 22.10 & 3 & 21.43 & 68.32 \\
\hline Alstonia boonei & Apocynaceae & 4538 & 15.86 & 28 & 29.47 & 3 & 21.43 & 66.76 \\
\hline Musanga cecropioides & Moraceae & 6506 & 22.74 & 20 & 21.05 & 3 & 21.43 & 65.22 \\
\hline Terminelia superba & Combretaceae & 7546 & 26.38 & 11 & 11.58 & 2 & 14.29 & 52.25 \\
\hline Anthocleistra vogelii & Potaliaceae & 2924 & 10.22 & 15 & 15.79 & 3 & 21.43 & 47.44 \\
\hline$\Sigma 5$ species & $\Sigma 5$ families & 28605 & 100.00 & 95 & 100.00 & 14 & 100.00 & 300.00 \\
\hline HIS & Apocynaceae & 5028 & 22.79 & 11 & 36.67 & 3 & 25.00 & 84.46 \\
\hline Alstonia boonei & Arecaceae & 6942 & 31.47 & 6 & 20.00 & 3 & 25.00 & 76.47 \\
\hline Elaeis guineensis & Potaliaceae & 3850 & 17.45 & 8 & 26.67 & 3 & 25.00 & 69.12 \\
\hline Anthocleistra vogelii & Hyperiaceae & 3218 & 14.59 & 3 & 10.00 & 2 & 16.67 & 41.26 \\
\hline Harungana madagascariensis & Pandanaceae & 3020 & 13.69 & 2 & 6.67 & 1 & 8.33 & 28.69 \\
\hline Pandanus candelabrum & $\Sigma 5$ families & 22058 & 100.00 & 30 & 100.00 & 12 & 100.00 & 300.00 \\
\hline$\Sigma 5$ species &
\end{tabular}

$R_{d}=$ relative density; $R_{f}=$ relative frequency, $R_{D}=$ relative dominance; $B A=$ basal area; $L I S=$ less impacted site; HIS $=$ highly impacted site 


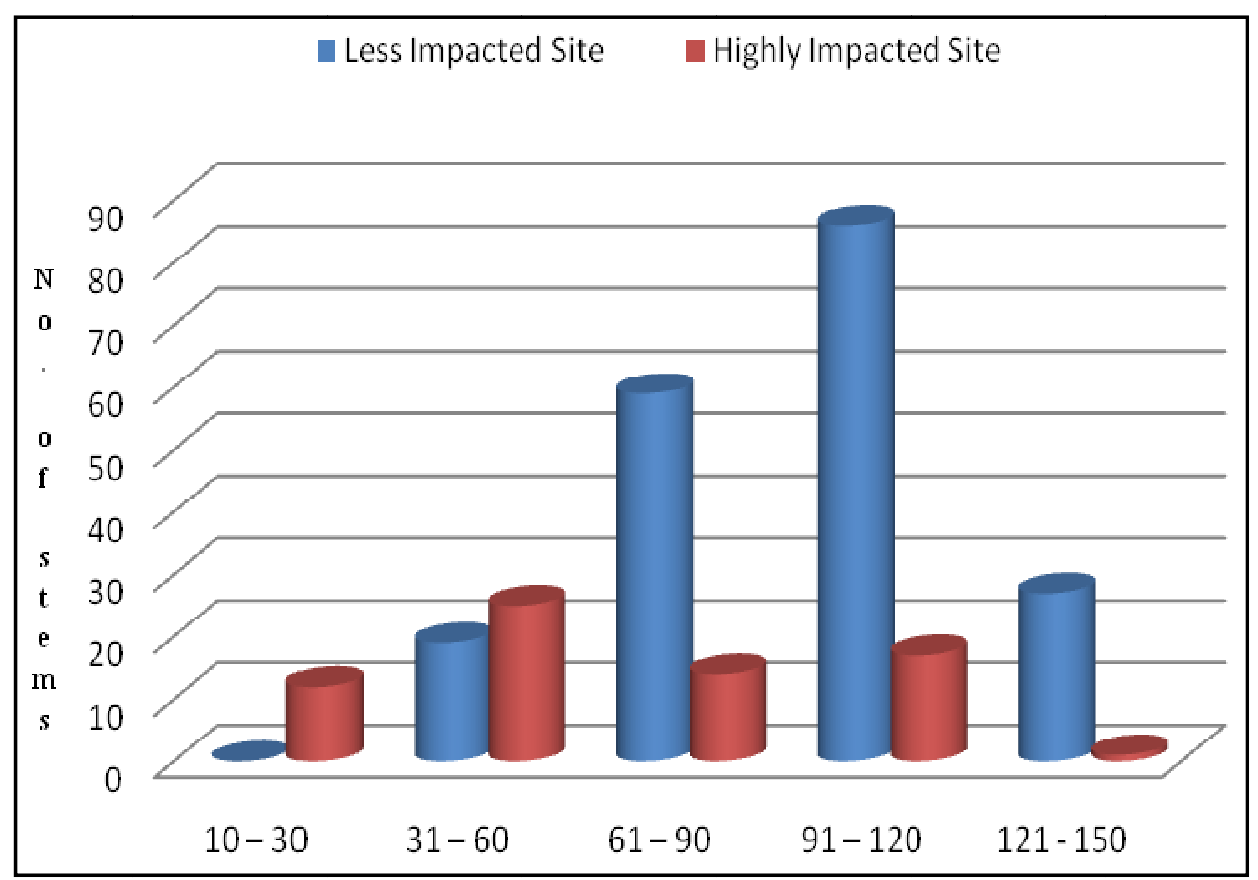

Figure 1. Stem diameter distribution of tree species 